\title{
Global marine primary production constrains fisheries catches
}

\author{
Emmanuel Chassot ${ }^{1, *}$, Sylvain Bonhommeau ${ }^{1}$, Nicholas K. Dulvy $^{2}$, Frédéric Mélin ${ }^{3}$, Reg Watson ${ }^{4}$, \\ Didier Gascuel ${ }^{5}$ and Olivier Le Pape ${ }^{5}$
}

\footnotetext{
${ }^{1}$ UMR 212 EME, IRD-IFREMER-UM2, Centre de Recherche Halieutique Méditerranéenne et Tropicale, Avenue Jean Monnet, BP 171, 34200 Sète, France

2 Earth to Ocean Research Group, Simon Fraser University Burnaby, BC V5A 1S6, Canada

${ }^{3}$ European Commission, Joint Research Centre, Institute for Environment and Sustainability, I-21027 Ispra (VA), Italy

${ }^{4}$ Sea Around Us project, Fisheries Centre, University of British Columbia, 2202 Main Mall, Vancouver, BC V6T

1Z4, Canada

${ }^{5}$ Université Européenne de Bretagne, UMR ESE 985, INRA - Agrocampus Ouest, 65 rue de St Brieuc, CS

84215, 35042 Rennes, France
}

*: Corresponding author : Emmanuel Chassot, email address : $\underline{\text { emmanuel.chassot@ird.fr }}$

\begin{abstract}
:
Primary production must constrain the amount of fish and invertebrates available to expanding fisheries; however the degree of limitation has only been demonstrated at regional scales to date. Here we show that phytoplanktonic primary production, estimated from an ocean-colour satellite (SeaWiFS), is related to global fisheries catches at the scale of Large Marine Ecosystems, while accounting for temperature and ecological factors such as ecosystem size and type, species richness, animal body size, and the degree and nature of fisheries exploitation. Indeed we show that global fisheries catches since 1950 have been increasingly constrained by the amount of primary production. The primary production appropriated by current global fisheries is $17-112 \%$ higher than that appropriated by sustainable fisheries. Global primary production appears to be declining, in some part due to climate variability and change, with consequences for the near future fisheries catches.
\end{abstract}

Keywords: Bottom-up $\bullet$ Large Marine Ecosystem • quantile regression • sustainable fishing 


\section{Introduction}

Fisheries have long been thought inexhaustible because of the vastness of the oceans that represent more than $70 \%$ of the surface of planet Earth. Over time, technology has advanced and fishing has progressively spread over the world oceans to affect marine species at lower trophic levels and in offshore deeper waters (Pauly et al. 2003; Essington et al. 2006). After a long period of steady increase, cumulative world marine fisheries catches stabilised in the mid-1990s at between 75 and $85 \times 10^{6}$ tons (Watson \& Pauly 2001). Such stability might actually be spurious, instead it is likely that global fisheries catches are declining and the decline has been masked by underreporting and misreporting of catch by countries combined with large environmentally-forced fluctuations in the catch of small pelagic species, such as the Peruvian anchoveta (Watson \& Pauly 2001). The decrease in global catch might be explained by the sequential depletion of individual stocks, which in the past would have been balanced by fisheries expansion to new opportunities in the high seas and into deeper water or by the exploitation of lower trophic levels (Pauly et al. 2002). Although limited empirical evidence has been provided to date, the attainment of a maximum of global catch is consistent with fundamental energetic limits to fisheries exploitation (Ryther 1969).

Solar radiation is the main external source of energy for marine ecosystems. More than $90 \%$ of oceanic productivity is fixed by phytoplankton which is then transferred through food webs by predation and lost through metabolism (Lindeman 1942; Duarte \& Cebrian 1996). The total fish and invertebrate production in an ecosystem results from the conversion of organic matter at each trophic level. This production depends on ecological features such as the number of feeding links, the efficiency of energy transfer from one trophic level to the next, and temperature-dependent metabolic kinetics in aquatic food web (Lindeman 1942; Ryther 1969; Iverson 1990; Ernest et al. 2003; Gascuel et al. 2008), and on ecosystem-specific features such as ecosystem size (Post et al. 2000), species richness (Frank et al. 2007), and consumer body size (Denney et al. 2002). In addition, the total secondary production available to fisheries depends upon the degree of fishing mortality and the nature of fisheries targeting of different trophic levels in the food web. Fisheries focusing only on lower trophic levels have the potential to appropriate orders of magnitude more energy than those focused on top predators (Pauly \& Christensen 1995; Gascuel \& Pauly 2009). 
Two opportunities enable a global scale exploration of the relationship between primary production and fisheries catches: the recognition and description of large biogeochemical and biologically consistent provinces (Large Marine Ecosystems) and the advent of satellite monitoring of ocean color and primary productivity. Large Marine Ecosystems encompass similar physical and ecological features, such as hydrography and productivity and provide convenient spatial units to test whether patterns of correlations between primary production and fisheries catches observed for some regions also persist at a global scale (Ware \& Thomson 2005; Chassot et al. 2007; Frank et al. 2007). Ocean primary productivity is inherently variable over short temporal (daily) and spatial (meter) scales, synoptic views are difficult to achieve with oceanographic ships which cross oceans at the speed of a bicycle. The only high frequency, basin-scale sampling of oceanic primary production is available from satellites (Longhurst 1998).

Here, we test the relationship between marine primary production and fisheries catches across the world's Large Marine Ecosystems. Primary production estimates in each LME were combined with global catch statistics that account for illegal and unreported fishing (Agnew et al. 2009). First, we test the degree to which primary production but also ecosystem features (type and size of ecosystem, sea surface temperature, species richness) and the degree and nature of fisheries (level of pressure, trophic and size structure of the catch) explain the spatial variation in fisheries catches. Second, we explore the degree to which global fisheries catches are constrained by primary production using quantile regression models.

\section{2, MATERIALS AND METHODS}

\section{Estimating primary production}

Annual estimates of primary production (PP) in each Large Marine Ecosystem over the period 2000-2004 were derived from averaged monthly global maps of surface concentrations of chlorophyll-a based on the Sea-viewing Wide Field-of-View Sensor (SeaWiFS, NASA) global time series (McClain et al. 2004). PP was computed from the surface concentration of the chlorophyll-a pigment, which serves as a proxy for algal biomass, using a wavelength- and depth-resolved model (Longhurst et al. 1995), further 
details are in the supplementary material online (Fig. S1). The PP estimates obtained at global scales with this approach were broadly consistent with those from other models driven by ocean colour data in terms of global average (47 $\mathrm{Pg} \mathrm{C} \mathrm{yr}^{-1}$ ) as well as spatial distribution (Carr et al. 2006) and compared favourably with a set of PP field measurements collected in the Equatorial Pacific and assembled for an international intercomparison exercise (Friedrichs et al. 2009). For long term analysis, we assumed that PP estimates during 2000-2004 reflect the large-scale spatial gradients in PP since 1950; this assumption is later discussed.

\section{Fisheries catches}

Annual catch data, including all quantities landed for both food and feed purposes, were available from spatially resolved global catch datasets prepared by the Sea Around Us project (http://www.seaaroundus.org/). Time series of catch data were derived from the harmonized global catch statistics of the Food and Agriculture Organization (FAO) of the United Nations and several other sources including collaborative national catch reconstructions using rule-based procedures which assign catch to 30-minute spatial cells based on taxon distribution, and on the fishing patterns/arrangements of reporting countries (Watson et al. 2004). Catch data were corrected for illegal and unreported catches that can represent a substantial amount of fisheries catches (Agnew et al. 2009) The dataset was available for the period 1950-2004 and excluded (i) ecosystems where data were incomplete, insufficiently detailed or suspected to be unreliable (e.g. Yellow Sea; Watson \& Pauly 2001), (ii) catches from distant-water fleets (not allocated to fishing areas), and (iii) large and medium pelagic species that can migrate outside and between LME boundaries. Thus, the dataset included resident species defined as populations that occupy the continental margin year-round and undertake only spatially limited seasonal migrations (Ware \& Thomson 2005). As a result, the following 10 of the 64 LMEs were excluded from the analysis: Antarctic, Arctic Ocean, Beaufort Sea, Chukchi Sea, East China Sea, East Siberian Sea, Hudson Bay, Kara Sea, Laptev Sea, and Yellow Sea. The remaining 54 LMEs considered here represented more than $68 \%$ of the world fisheries catches during 1950-2004. The selected resident non-migratory fishes and invertebrates corresponded to $90 \%$ of total catch in these LMEs during 1950-2004. 


\section{Primary production required to support fishery catches}

To convert fisheries catches into comparable energy units, we calculated the primary production required (PPR) to support fishery catches in $\mathrm{t} \mathrm{C} \mathrm{km} \mathrm{km}^{-1}$. This allows comparison of fisheries catches consisting of species from different trophic levels (Ryther 1969; Pauly \& Christensen 1995). The primary production required to produce the catches was calculated as following:

$$
P P R_{j}=\sum_{i=1}^{n}\left(\frac{C_{i j}}{9}\right) \times\left(\frac{1}{T E_{j}}\right)^{T L_{i}-1}
$$

where $C_{i j}$ is the catch (in metric tons) of species $i$ in $\operatorname{LME} j, T E$ is the trophic transfer efficiency in $\operatorname{LME} j$, i.e. the proportion of prey production converted to predator production, $T L_{i}$ is the trophic level of species $i$ and $n$ is the number of species harvested in the LME. PPR estimates were based on a conservative 9:1 ratio for the conversion of wet weight to carbon (Strathmann, 1967).

Trophic levels derived from stomach content data were extracted from the FishBase database (Froese \& Pauly 2009) and assigned to each species, assuming they were stable from year to year and valid for the area covered by the study.

\section{Potential covariates of the primary production and fisheries catch relationship}

Several candidate covariates that represent major physical and ecological processes within large marine ecosystems were considered as predictors of fisheries catch. In addition to primary production, we selected 7 covariates for which data are available at LME scale: ecosystem type, sea surface temperature (Jennings et al. 2008), ecosystem size (Post et al. 2000), species richness (Frank et al. 2007), fishing pressure (Coll et al. 2008), mean trophic level (Gascuel et al. 2008), and maximum average body length (Denney et al. 2002). In doing so we explore the link between energy and fisheries production while accounting for all other major hypotheses.

a. Ecosystem type 
Three ecosystem types were considered: upwelling, temperate, and tropical. Transfer efficiency TE was derived from a synthesis of ecosystem models and set equal to $5 \%$, $10 \%$, and $14 \%$ for upwelling, temperate and tropical ecosystems, respectively (Libralato et al. 2008; Coll et al. 2008), and assumed constant for each trophic level during 1950-2004.

b. Sea surface temperature (SST)

The SST distributions, obtained from the Physical Oceanography Distributed Active Archive Center (PO. DAAC, Jet Propulsion Laboratory), are provided by the AVHRR Pathfinder data set (version 5) as monthly maps (1985-2004) with a resolution of $4 \mathrm{~km}$ (http://podaac.jpl.nasa.gov/). Only the data points associated with the highest level of quality flags were considered.

\section{c. Ecosystem size (ES)}

The surface area of each Large Marine Ecosystem was computed using a geographic information system and assumed to be a good proxy of ecosystem size.

d. Species richness (SR)

The number of marine fishes in each Large Marine Ecosystem was derived from the Sea Around Us project (http://www.seaaroundus.org/). We calculated species richness per unit of area in each LME to account for the underlying species area relationship.

e. Fishing pressure $\left(P_{\text {sust }}\right)$

Fishing has both direct and indirect effects on fish populations and marine ecosystems (e.g. decline in stock abundance and habitat degradation), eventually affecting their structure and functioning (Garcia et al. 2003). Overexploitation of single species limits the catch that can be taken, but in a multispecies context the removal of relatively unproductive high trophic level predatory species can lead to increased fisheries catch potential through the proliferation of smaller, more-productive individuals and species (e.g. Gascuel et al. 2008). As marine ecosystems exhibit large differences in fisheries history, 
levels of exploitation, and trophic structure of the catch; an index of the overall ecosystem effects of fishing was used to account for differences in fishing pressure. The mean annual probability of sustainable fishing ( $P_{\text {sust }}$ ) was recently developed to assess the level of overfishing at ecosystem scale based on the total removal of secondary production compared to reference levels derived from ecosystem models (Libralato et al. 2008; Coll et al. 2008). The mean annual value of $P_{\text {sust }}$ calculated for the period 2000-2004 accounting for discards and 30\% illegal and unreported catch estimates was used. Lower probabilities of sustainable fishing $P_{\text {sust }}$ indicate higher fishing pressures (Coll et al. 2008) .

f. Mean trophic level of the catch (MTL)

For each LME, the Mean Trophic Level (MTL) of the catch, computed as the weighted average of trophic level of harvested species, was used to describe the position of the fishery in the food web during 2000-2004 (Froese \& Pauly 2009).

g. Average maximum length $\left(L_{\max }\right)$

Fisheries yield and sustainability is, to some degree, determined by the intrinsic population growth rate of the target species - for a given fishing mortality, shark fisheries are likely to be less sustainable and less productive than anchovy fisheries (Reynolds et al. 2005). We used body size as a proxy for the intrinsic rate of population increase, based on theoretical and empirical evidence for a scaling relationship between body size and the intrinsic rate of population increase (Denney et al. 2002, Savage et al. 2004). The average maximum length of the fish catch within each LME (Froese \& Pauly 2009), computed as the weighted average of maximum length of harvested species, was used as a surrogate for the intrinsic growth rate of increase of the fish community (Denney et al. 2002).

\section{Testing for covariates of fisheries catch production}

We used linear models to test for the effects of fishing pressure, average maximum length, sea surface temperature, mean trophic level, ecosystem size, species richness, log-primary production and ecosystem type on fisheries catches (log-PPR) during the period 2000-2004. No interaction effect was included in the model. Log-transformation of the response variable (PPR) and the primary production covariate enabled to remove 
skew and minimize the large standard deviations in the data. The following model was considered:

$$
\log \left(P P R_{j}\right)=\text { Psust }_{j}+\text { Lmax }_{j}+S S T_{j}+M T L_{j}+E S_{j}+S R_{j}+\log \left(P P_{j}\right)+E T_{j}+\varepsilon_{j}
$$

where $j$ indexes LME, $P_{\text {sust }}$ is the probability of sustainable fishing, $L_{\max }$ is the average maximum length of the catch, SST is the sea surface temperature, MTL is the mean trophic level of the catch, ES is the ecosystem size, $S R$ is the species richness, $P P$ is the primary production, $E T$ is the ecosystem type. $\varepsilon_{j}$ was modeled as an independent, normally distributed random variable with mean zero and constant variance. The assumptions of homoscedasticity and Gaussian error were checked through the residuals. Models were evaluated using the Akaike information criterion (AIC).

\section{Inferring constraints or limits using quantile regression}

Changes in the slope of the regression models were used to investigate whether primary production may constrain fishery catches. Quantile regressions are used to identify limiting factors when relating ecological variables (e.g. fish abundance) to environmental indices (Cade \& Noon 2003; Planque \& Buffaz 2008). A factor is inferred to be limiting when the slope tends to be steeper for upper quantiles and when it is significantly different from zero for high quantiles (Planque \& Buffaz 2008). In particular, linear regression models for quantiles ranging from $10 \%$ to $90 \%$ by steps of $10 \%$ were used to describe how the range of catch and PPR levels varied according to PP over long- (1950-2004) and short-term scales (2000-2004). The 90\% quantile was used as a proxy of the maximum fishery production, although the upper regression quantiles do not describe the exact limit of the distribution function.

We tested whether the fishery catch changed over time through the slope of linear model fitted between mean annual values of catch and PPR per LME averaged over (i) the recent period (2000-2004) and (ii) the long-term (1950-2004). We then estimated the slope of the $90 \%$ quantile regressions fitted to data grouped by 5-year periods over 1950-2004 to analyse the temporal changes in the maximum of PPR/PP ratio, considered as an index of LME exploitation (Pauly \& Christensen 1995; Libralato et al. 2008). 
Defining the upper limit of fisheries catch is a prerequisite to assess current levels of fishing relative to benchmarks and give insights into future fisheries catch. We used the slopes estimated from the $90 \%$ quantile linear regression models to predict the maximum global fisheries catches for 2000-2004, considering that all Large Marine Ecosystems could be exploited at maximum levels given their ecosystem-specific primary production. Similarly, sustainable levels of maximum global fisheries catch have been calculated from the $90 \%$ quantile regression slopes estimated using solely LMEs where the probability of sustainable fishing $P_{\text {sust }}$ was higher than 75\% and 95\%. Quantile regression models were all fitted to data without intercept and performed using the R package quantreg (Koenker 2009).

\section{3, RESULTS}

\section{A large spatial variability in fisheries catch}

The mean annual catch during 2000-2004 for all species in the 54 LMEs was $68 \times 10^{6} \mathrm{t} \mathrm{y}^{-1}$ $\left(\mathrm{SD}=4 \times 10^{6} \mathrm{t} \mathrm{y}^{-1}\right)$, corresponding to a PPR of $3.5 \times 10^{9} \mathrm{t} \mathrm{C} \mathrm{y}^{-1}\left(\mathrm{SD}=0.09 \times 10^{9} \mathrm{tC}^{-1}\right)$. The LMEs showed strong differences in fishery catch over the long term (1950-2004) and recent period (2000-2004), without any clear pattern associated with ecosystem type (Fig. 1a,c). In the 2000s, approximately $1 \mathrm{t} \mathrm{km}^{-2} \mathrm{y}^{-1}$ of fish catch is derived from $600 \mathrm{t} \mathrm{C} \mathrm{km}^{-2} \mathrm{y}^{-1}$ of primary production. Three of the 54 LMEs showed high levels of mean annual catch when averaged over the whole period 1950-2004 (Fig. 1a): the North Sea (PP = 919 t C $\mathrm{km}^{-2} \mathrm{y}^{-1}$, catch $\left.=5.6 \mathrm{t} \mathrm{km}^{-2} \mathrm{y}^{-1}\right)$, the Humboldt Current $\left(P P=822 \mathrm{t} \mathrm{C} \mathrm{km}^{-2} \mathrm{y}^{-1}\right.$, catch $=4.0 \mathrm{t}$ $\left.\mathrm{km}^{-2} \mathrm{y}^{-1}\right)$, and the Iceland shelf $\left(P P=561 \mathrm{t} \mathrm{C} \mathrm{km}^{-2} \mathrm{y}^{-1}\right.$, catch $=3.9 \mathrm{t} \mathrm{km}^{-2} \mathrm{y}^{-1}$ ). These LMEs were still the most productive in 2000-2004, with the Humboldt LME reaching an average fisheries catch of $7.0 \mathrm{t} \mathrm{km}^{-2} \mathrm{y}^{-1}$, being by far the most productive ecosystem of the world (Fig. 1c). The high catch levels in these LMEs in the recent period were mainly due to the catch being comprised largely of low trophic level (TL) species, i.e. sandeels (Ammodytes spp.; $\mathrm{TL}=3.1$ ), anchovy (Engraulis ringens; $\mathrm{TL}=2.7$ ), and capelin (Mallotus villosus; $\mathrm{TL}=$ 3.05) for the North Sea, Humboldt, and Iceland Shelf, respectively.

The conversion of catch weights into the Primary Production Required to support these fisheries reduced the spatial variability in fishery catch among LMEs (Fig. 1b,d) and showed that eastern boundary upwelling systems exhibit the highest values of PPR. The 
LMEs where the highest proportion of primary production is appropriated by fisheries catch over 1950-2004 include the Canary, Humboldt, and Benguela eastern boundary current upwelling ecosystems, with values of $44 \%, 50 \%$, and $24 \%$, respectively in the 2000s. Again the high PPR can be attributed to the high catches of small low trophic level pelagic species such as anchovies (Engraulis spp.), sardines (Sardina pilchardus and Sardinops spp.), and sardinellas (Sardinella spp.) in upwelling LMEs and the low transfer efficiency of this type of ecosystems.

\section{Disentangling the major factors explaining fisheries catch}

The spatial variance in global fisheries catches was best explained by four variables which explained $77 \%$ of the inter-LME variance in log-PPR: primary production (log-PP), the probability of sustainable fishing $\left(P_{\text {sust }}\right)$, the average maximum length $\left(L_{\max }\right)$, and ecosystem type (ET). Primary production, ecosystem type, and fishing pressure explained most of the variance (Table 1). Other potential covariates, sea surface temperature (SST), mean trophic level (MTL), ecosystem size (ES), and fish species richness (SR) were not significantly different from zero and hence removed from the final model. The estimates of the ecosystem type parameters were higher for upwellings than tropical and temperate ecosystems, in accordance with the transfer efficiency we used to calculate PPR.

The prediction of Primary Production Required in each LME was reasonably accurate (Normalized Root Mean Square Error $=12 \%$ ). The model prediction of global PPR was $3.74 \times 10^{9} \mathrm{t} \mathrm{C} \mathrm{y}^{-1}$ which is very similar to the actual PPR computed from the data $\left(3.46 \times 10^{9}\right.$ $t \mathrm{C}^{-1}$ ). More sustainable fisheries would decrease the PPR, the negative coefficient suggests PPR significantly decreased with higher values of $P_{\text {sust }}$ (Table 1). Exploitation of smaller-bodied fishes results in greater fisheries catch; the negative coefficient shows that PPR significantly decreased with $L_{\max }$ (Table 1 ). Primary production appears to constrain fisheries catches since PP positively and significantly affects PPR, once ecosystem type, degree $\left(P_{\text {sust }}\right)$ of the fisheries, and intrinsic population growth $\left(L_{\max }\right)$ are accounted for (Table 1). 


\section{Primary production as a limiting factor of fisheries catch}

Primary production limits average and maximum fisheries catch across the world at the LME scale over both short and longer time scales (Fig. 1a, c and S2). The limitation has become increasingly apparent as regression slopes become steeper in more recent time periods (Fig. 2). The significant relationship found between long-term (1950-2004) and recent catch (2000-2004) (slope $=0.76$, adjusted $r^{2}=0.82, p<0.001$ ) revealed that the spatial gradients in fisheries catches were consistent through time (Fig. S3-S4).

\section{Increasing levels of fishing exploitation through time}

There has been a steady increase in the level of exploitation (PPR/PP) with a maximum value of $16 \%$ during $2000-2004$, based on the change in the $90 \%$ quantile regression slope (Fig. 3 and S5). The stability of the PPR/PP ratio in the last 20 years could suggest that current fishing patterns, and especially the fishing strategy currently applied in term of trophic levels that are targeted, may not allow any further increase in LME fisheries catch relative to primary production levels.

\section{Predictions of maximum global fisheries catch}

The potential maximum of global catch was predicted to be $146 \times 10^{6} \mathrm{t}^{-1}$ during 2000-2004 based on the 90\% quantile regression model (Table 2). The mean total catch during 2000-2004 exceeded the maximum global fisheries catch predicted from the Large Marine Ecosystems where fishing is considered sustainable by $17 \%$ and $112 \%$ for $\mathrm{P}_{\text {sust }}>$ $75 \%$ and $P_{\text {sust }}>95 \%$, respectively (Table 2 ). These results emphasize the dependence of the current levels of fisheries catch on the unsustainable exploitation of these Large Marine Ecosystems.

\section{DISCUSSION}

\section{Linkage between primary production and fisheries catches}

Globally, fisheries catches are increasingly constrained by the primary productivity of the 
underlying Large Marine Ecosystems (Pauly \& Christensen, 1995). While this has been shown at regional scales (Ware \& Thomson, 2005; Chassot et al., 2007), the novelty of the present work is to show that primary production constrains fisheries catches, while accounting for ecosystem and fisheries features. Here, we show that the primary production appropriated by fisheries catches depends on the scale and nature of fisheries, with heavily-exploited fisheries and those fisheries targeting the smallest fish species appropriating more primary production per tonne of catch. In addition, comparison of longterm vs. recent catches showed that the regional gradients in fisheries catches have not been modified during the last half century, in spite of different histories and developments of the LME fisheries combined with increasing exploitation intensity. This coupling between marine production and fisheries catches reveals that similar mechanisms underlie the functioning of marine ecosystems worldwide. Based on the trophodynamic approach of Lindeman (1942), we suggest these patterns are consistent with energetic transfers along the food web, from the biomass produced by phytoplankton photosynthesis to upper trophic levels.

\section{Global open-access databases for characterizing ecosystem-level ecological patterns}

The advent of open-access global datasets derived from remote sensing, the compilation of ecological studies, i.e. estimates of trophic levels, average maximum length, transfer efficiency, and species richness, and fishery statistics allowed us to unveil the relative importance of bottom-up and extrinsic control of fisheries catch at global scale. The availability of global databases such as SeaWiFS, FishBase, and ECOwEB (Cohen, 1989) has proven to be a fundamental tool for detecting ecosystem-level ecological patterns and for testing for hypotheses on general laws and rules in ecology (e.g. Pimm et al. 1991). The development of access web services and data management infrastructures based on international collaborative work (e.g. SeaDataNet; http://www.seadatanet.org/) combined with openness of datasets collected through public funds is a major step toward the improvement of our knowledge on the structure and functioning of marine ecosystems.

Due to the short span of SeaWiFS data, we assumed time-consistency in the spatial gradients of primary production although significant changes in phytoplankton may have occurred in the last decades (Reid et al. 1998). Comparison of chlorophyll climatologies 
derived from historical in situ data going back to the 1950 s and remote sensing data sets showed that seasonal and spatial patterns are consistent at global scale (Conkright \& Gregg 2003). This was supported by our data as the spatial differences in primary production were generally greater than the temporal variations observed in the Large Marine Ecosystems for the period 2000-2004. There are still large uncertainties associated with estimates of primary production in the optically complex waters of some coastal areas, especially when turbidity is increased owing to suspended and dissolved materials. Furthermore, annual primary production estimates are seasonally-biased in Large Marine Ecosystems of northern and southern latitudes due to cloud and ice coverage. However, these high latitude ecosystems face the biggest but uncertain anticipated potential impacts from climate change on primary production due to reduced sea ice and early impact from ocean acidification. Some of these physical changes are anticipated to lead to high species turnover due to local extinction and invasion in the Arctic and the sub-polar region of the Southern Ocean (Reid et al. 2007; Cheung et al. 2009). Primary production distributions provided by ocean color and appropriate models remain the major source of information for a synoptic and consistent mapping of phytoplankton activity over large spatial and temporal scales (Longhurst, 1998). A better knowledge of climate impacts on fisheries will require focusing on understanding primary production and energy transfers in both coastal waters and high latitude Large Marine Ecosystems.

Given the lack of precise information on transfer efficiency in the complex marine food webs of the Large Marine Ecosystems, we assumed constant ecosystem type-specific transfer efficiency values (Libralato et al. 2008). These values were based on a set of ecosystem models constructed from large datasets and steady state assumptions. Assuming constant transfer efficiency in dynamic food webs might affect our perception of the spatio-temporal variability of energy transfers from primary production to upper trophic levels. Further fundamental work is required to analyse trade-offs between transfer efficiencies and predator-prey mass ratio and how these parameters vary across environments (Jennings et al. 2008). 
We used the probability of sustainability (Coll et al. 2008) as a measure of fishing pressure in the Large Marine Ecosystems. Despite some limitations, this index is based on a suite of indicators of overfishing that account for fishing effects at both population and ecosystem levels (Murawski 2000, Coll et al. 2008). In addition to the direct impact of overfishing on stock dynamics, the probability of being sustainably fished includes several components such as non-harvest mortality and habitat degradation that affect ecosystem properties and fisheries catches (Murawski 2000). Estimating an index of fishing pressure, i.e. fishing mortality at the scale of a population from observations of fishing effort (e.g. number of days at sea) is already a major task faced by fisheries scientists when assessing the state of fish stocks. Inferring fishing pressure estimates from the population to the community and whole ecosystem can be very complex due to interaction effects such as prey release which can increase secondary production and other fishing effects such as habitat degradation (Garcia et al. 2003). A better compilation and accessibility of global fishing effort and mortality estimates from Regional Marine Fisheries Organisations (RMFOs) and research institutes will ultimately facilitate comparative analyses among exploited ecosystems.

Life-history traits have been shown to affect the response of fish stocks to fisheries exploitation, with larger and later maturing species being less able to withstand a given rate of fishing mortality than their smaller earlier maturing counter-parts (Jennings et al. 1998). Maximum length is a key life-history trait and has been shown to be highly correlated with recruit and adult production and density dependence (Denney et al. 2002). Using the FishBase global information system (Froese \& Pauly 2009), we computed an average maximum length within each Large Marine Ecosystem to synthesize life-history traits of the fish community in order to account for its capacity to sustain fishing mortality. Since detailed information on population dynamics (e.g. stock-recruitment relationship) is only available for fish stocks assessed within the framework of the RMFOs, maximum body size currently provides the most appropriate proxy for intrinsic population growth for the 901 exploited fish species considered in the present analysis (Denney et al. 2002).

\section{Global fisheries catch in a context of climate change}

Our results confirm the linkage between primary production and fisheries catches to estimate the potential maximum catch of the world oceans based on marine systems 
described by different ecological transfer efficiencies (Ryther 1969; Pauly \& Christensen 1995). In a context where cumulative world fisheries catches have already shown signs of decline since the mid-1990s after a long period of steady increase (Watson \& Pauly 2001; Pauly et al. 2002), our estimates indicate that current total fisheries catch could exceed sustainable reference levels, compared to LMEs where fishing is considered sustainable (Table 2). PPR predictions from the linear model were found to be in good agreement with observed data and consistent with global estimates of Pauly $(1996)\left(\sim 3.10^{9} \mathrm{t} \mathrm{C} \mathrm{y}^{-1}\right)$.

Our model could be used to predict potential changes in fisheries catch given future mean maximum size, levels of fishing sustainability, and projections of marine production following the Intergovernmental Panel on Climate Change (IPCC) scenarios. The recent analysis of 50-year time series of sea surface temperature (SST) has shown warming trends in most of the LMEs of the world, with acceleration in the late 1970s-early 1980s and strong regional variations in SST change (Belkin 2009). Primary production remote sensing observations revealed that the recent surface temperature increase has triggered large spatial changes and a reduction in the global production of ocean phytoplankton since the early 1980s (e.g. Behrenfeld et al. 2006). This trend is especially marked outside the equatorial zone, where the areas of low chlorophyll production have recently expanded significantly (Polovina et al. 2008). Following our analysis, a reduction in primary production could have global negative impacts on fisheries catch and exacerbate current trends of overfishing. Predictions of chlorophyll-a concentrations to climate warming derived from coupled atmosphere-ocean general circulation models indicate little overall change in PP by 2050 (Sarmiento et al. 2004). However these small changes at the global scale belie marked regional differences in the PP such as 17-42\% contraction of productive marginal sea ice biomes and 7-16\% expansion of the less productive subtropical oligotrophic gyres (Sarmiento et al. 2004). O'Connor et al. (2009) recently showed that the metabolic effects of temperature change will affect food web structure and productivity in mesocosms. Although the metabolic role of temperature is widely recognised (López-Urrutia et al. 2006; Jennings et al. 2008; Gascuel et al. 2008), temperature appears to be relatively unimportant compared to the other variables in our model. Outside the laboratory, the metabolic effect of temperature variation appears relatively unimportant at ecosystem scales compared to the level of primary production, mean body size, and degree of fisheries exploitation. 
Our results have an important bearing for ecosystem approaches to fisheries and future climate change impact on global fisheries catches. First, our results show that many sustainably fished ecosystems may actually be drawing down the balance of ecological capital by taking fisheries catches beyond that which can be sustained by current primary production. Second, predicted decline in global primary production might exacerbate current trends of overfishing and may not only lead to food security issues but also affect the human well-being and economies of many fishery-dependent countries.

\section{ACKNOWLEDGEMENTS}

The authors would like to thank the Ocean Biology Processing Group of NASA for the distribution of the SeaWiFS products. Authors acknowledge the support of the Sea Around Us Project, a scientific collaboration between the University of British Columbia and the Pew Environment Group, for harmonized global catch statistics. A Bundy, D Duplisea (DFO, Canada), P Cury (IRD, France), and DA Siegel (UCSB, USA) made useful comments to improve the manuscript. We thank M Barange, the Quest-Fish project, $L$ Harrisson (SFU, Canada), A Yool (SOC, UK), E Rivot (Agrocampus Ouest, France), W Blanchard and C. Minto (Dalhousie University, Canada) and J Bob Barde (IRD, France) for their support and three referees for constructive criticism. We finally thank T Platt and S Sathyendranath (DFO, Canada) for organising the SAFARI workshop.

\section{REFERENCES}

Agnew, D.J., Pearce, J., Pramod, G., Peatman, T., Watson, R., Beddington, J.R. et al. (2009). Estimating the Worldwide Extent of Illegal Fishing. PLOS ONE, 4, e4570.

Behrenfeld, M.J., O'Malley, R.T., Siegel, D.A., McClain, C.R., Sarmiento, J.L., Feldman, G.C. et al. (2006). Climate-driven trends in contemporary ocean productivity. Nature, 444, 752-755.

Belkin, I. (2009). Rapid warming of Large Marine Ecosystems. Progr. Oceanogr., 81, 207-213.

Cade, B. \& Noon, B. (2003). A gentle introduction to quantile regression for ecologists. Front. Ecol. Envir., 1, 412-420.

Carr, M.-E., Friedrichs, M.A., Schmeltz, M., Aita, M.N., Antoine, D., Arrigo, K.R. et al. (2006). A comparison of global estimates of marine primary production from ocean color. Deep-Sea Res. Part II, 53, 741-770.

Chassot, E., Mélin, F., Le Pape, O. \& Gascuel, D. (2007). Bottom-up control regulates fisheries production at the scale of eco-regions in European seas. Mar. Ecol. -Progr. Ser., 343, 45-55.

Cheung, W.W., Lam, V.W., Sarmiento, J.L., Kearney, K., Watson, R. \& Pauly, D. (2009). 
Projecting global marine biodiversity impacts under climate change scenarios. Fish Fish., 10, 235-251.

Cohen, J.E. (1989). Ecologists' Co-Operative Web Bank (ECOWeB). Version 1.0. Machine-readable data base of food webs. Rockfeller University, New York, USA.

Coll, M., Libralato, S., Tudela, S., Palomera, I. \& Pranovi, F. (2008). Ecosystem overfishing in the ocean. PLOS ONE, 3, e3881.

Conkright, M. \& Gregg, W. (2003). Comparison of global chlorophyll climatologies: In situ, CZCS, Blended in situ-CZCS and SeaWiFS. Int. J. Remote Sens., 24, 969-991.

Denney, N. H., Jennings, S. \& Reynolds, J. D. (2002). Life-history correlates of maximum population growth rates in marine fishes. Proc. Roy. Soc. Lond. B, 269, 2229-2237.

Duarte, C. M. \& Cebrian, J. (1996). The fate of marine autotrophic production. Limnol. Oceanogr., 41, 1758-1766.

Ernest, S.K.M., Enquist, B.J., Brown, J.H., Charnov, E.L., Gillooly, J.F., Savage, V.M. et al. (2003). Thermodynamic and metabolic effects on the scaling of production and population energy use. Ecol. Lett., 6, 990-995.

Essington, T., Beaudreau, A.H. \& Wiedenmann, J. (2006). Fishing through marine food webs. Proc. Natl. Acad. Sci., 103, 3171-3175.

Frank, K.T., Petrie, B. \& Shackell, N.L. (2007). The ups and downs of trophic control in continental shelf ecosystems. Trends Ecol. Evol., 22, 236-242.

Friedrichs, M.A., Carr, M., Barber, R.T., Scardi, M., Antoine, D., Armstrong, R.A. et al. (2009). Assessing the uncertainties of model estimates of primary productivity in the tropical Pacific Ocean. J. Mar. Syst., 76, 113-133.

Froese, R. \& Pauly, D. (2009). FishBase. World Wide Web electronic publication. Retrieved from www.fishbase.org.

Gascuel, D., Morissette, L., Palomares, D. \& Christensen, V. (2008). Trophic flow kinetics in marine ecosystems: toward a theoretical approach to ecosystem functioning. Ecol. Model., 217, 33-47.

Gascuel D., Pauly D. (2009). EcoTroph: modelling marine ecosystem functioning and impact of fishing. Ecol. Model., 220, 2885-2898.

Garcia, S.M., Zerbi, A., Do Chi, T. \& Lasserre, G. (2003). The ecosystem approach to fisheries. Issues, terminology, principles, institutional foundations, implementation and outlook. (FAO, Ed.) FAO Fisheries Technical Paper. Rome, Italy.

Iverson, R. (1990). Control of marine fish production. Limnol. Oceanogr., 35, 1593-1604.

Jennings, S., Mélin, F., Blanchard, J.L., Forster, R., Dulvy, N.K. \& Wilson, R. (2008). Global-scale predictions of community and ecosystem properties from simple ecological theory. Proc. Roy. Soc. Lond. B, 275, 1375-1383.

Jennings, S., Reynolds, J. D. \& Mills, S. C. (1998). Life history correlates of responses to fisheries exploitation. Proc. Roy. Soc. Lond. B, 265, 333-339.

Koenker, R. (2009). Quantreg: Quantile regression. R package version 4.30

Libralato, S., Coll, M., Tudela, S., Palomera, I. \& Pranovi, F. (2008). Novel index for quantification of ecosystem effects of fishing as removal of secondary production. Mar. Ecol. -Prog. Ser., 355, 107-129.

Lindeman, R.L. (1942). The trophic-dynamic aspect of ecology. Ecology, 23, 399-418.

Longhurst, A. (1998). Ecological geography of the sea. Academic Press, San Diego, USA.

Longhurst, A.R., Sathyendranath, S., Platt, T. \& Caverhill, C. (1995). An estimate of global primary production in the ocean from satellite radiometer data. J. Plank. Res., 17, 1245-1271.

López-Urrutia, Á., San Martin, E., Harris, R.P. \& Irigoien, X. (2006). Scaling the metabolic balance of the oceans. Proc. Natl. Acad. Sci. USA, 103, 8739-8744.

McClain, C.R., Feldman, G.C. \& Hooker, S.B. (2004). An overview of the SeaWiFS project 
and strategies for producing a climate research quality global ocean bio-optical time series. Deep-Sea Res. Part II, 51, 5-42.

Murawski, S. A. (2000). Definitions of overfishing from an ecosystem perspective. ICES J. Mar. Sci., 57, 649-658.

O'Connor, M.I., Piehler, M.F., Leech, D.M., Anton, A., Bruno, J.F. (2009). Warming and resource availability shift food web structure and metabolism. Plos Biol., 7, e1000178.

Pauly, D. (1996). One hundred million tonnes of fish, and fisheries research. Fish. Res., 25, 25-38.

Pauly, D., Alder, J., Bennett, E., Christensen, V., Tyedmers, P. \& Watson, R. (2003). The future of fisheries. Science, 302, 1359-1361.

Pauly, D. \& Christensen, V. (1995). Primary production required to sustain global fisheries. Nature, 374, 255-257.

Pauly, D., Christensen, V., Guénette, S., Pitcher, T.J., Sumaila, U.R., Walters, C.J. et al. (2002). Towards sustainability in world fisheries. Nature, 418, 689-695.

Pimm, S.L., Lawton, J.H. \& Cohen, J.E. (1991). Food web patterns and their consequences. Nature, 350, 669-674.

Planque, B. \& Buffaz, L. (2008). Quantile regression models for fish recruitmentenvironment relationships: four case studies. Mar. Ecol. -Progr. Ser., 357, 213-223.

Polovina, J.J., Howell, E.A. \& Abecassis, M. (2008). Ocean's least productive waters are expanding, Geophys. Res. Lett., 35, L03618.

Post, D. M., Pace, M. L. \& Hairston, N. G. (2000). Ecosystem size determines food-chain length in lakes. Nature, 405, 1047-1049.

Reid, P.C., Edwards, M., Hunt, H.G. \& Warner, A.J. (1998). Phytoplankton change in the North Atlantic. Nature, 391, 546.

Reid, P.C., Johns, D.G., Edwards, M., Starr, M., Poulin, M. \& Snoeijs, P. (2007). A biological consequence of reducing Arctic ice cover: arrival of the Pacific diatom Neodenticula seminae in the North Atlantic for the first time in 800000 years. Glob. Change Biol., 13, 1910-1921.

Reynolds, J.D., Dulvy, N.K., Goodwin, N.B. \& Hutchings, J.A. (2005). Biology of extinction risk in marine fishes. Proc. Roy. Soc. Lond. B, 272, 2337-2344.

Ryther, J. H. (1969). Photosynthesis and fish production in the sea. Science, 166, 72-76.

Sarmiento, J.L., Slater, R., Barber, R., Bopp, L., Doney, S.C., Hirst, A.C. et al. (2004). Response of ocean ecosystems to climate warming. Glob. Biogeochem. Cycle, 18, GB3003.

Savage, V.M., Gillooly, J.F., Brown, J.H., West, G.B. \& Charnov, E.L. (2004). Effects of body size and temperature on population growth. Am. Nat., 163, 429-441.

Strathmann, R.R. (1967). Estimating organic carbon content of phytoplankton from cell volume or plasma volume. Limnol. Oceanogr., 12, 411-418.

Ware, D.M. \& Thomson, R.E. (2005). Bottom-up ecosystem trophic dynamics determine fish production in the Northeast Pacific. Science, 308, 1280-1284.

Watson, R. \& Pauly, D. (2001). Systematic distortions in world fisheries catch trends. Nature, 414, 534-536.

Watson, R., Kitchingman, A., Gelchu, A. \& Pauly, D. (2004). Mapping global fisheries: sharpening our focus. Fish Fish., 5, 168-177. 


\section{Table s}

Table 1 Primary production, fishing pressure, and average maximum length of fisheries catches best explain the spatial variance in fisheries catch among Large Marine Ecosystems. Summary table of the parameter estimates, degrees of freedom, standard errors, p-value, and percentage of deviance explained for the selected model. $j$ index LME and $\varepsilon$ is a normally distributed random variable with mean zero and constant variance

Table 2 Global fisheries catch during 2000-2004 and maximum global fisheries catch (MGFC) predicted from quantile linear regression models for different levels of sustainability. MGFC, MGFC 75, MGFC $_{95}$ computed for all Large Marine Ecosystems, LMEs where $\mathrm{P}_{\text {sust }}>75 \%$, and LMEs where $\mathrm{P}_{\text {sust }}>95 \%$, respectively. Values between brackets indicate $95 \%$ confidence interval

\section{TABLE 1}

\begin{tabular}{|c|c|c|c|c|c|}
\hline Explanatory variable & $\begin{array}{l}\text { Paramet } \\
\text { er value }\end{array}$ & $\begin{array}{l}\text { Degrees of } \\
\text { freedom }\end{array}$ & $\begin{array}{l}\text { Standard } \\
\text { Error }\end{array}$ & $\begin{array}{c}\mathrm{P}- \\
\text { value }\end{array}$ & $\begin{array}{l}\text { \% Deviance } \\
\text { explained }\end{array}$ \\
\hline $\begin{array}{l}\text { Probability of sustainable } \\
\text { fishing } P_{\text {sust }}\end{array}$ & $-0,0311$ & 1 & 0,0046 & $\begin{array}{c}< \\
0.001\end{array}$ & 28,24 \\
\hline Average maximum length $L_{\max }$ & $-0,0384$ & 1 & 0,0093 & $\begin{array}{c}< \\
0.001\end{array}$ & 6,28 \\
\hline Primary production log-PP & 1,3755 & 1 & 0,2793 & $\begin{array}{c}< \\
0.001\end{array}$ & 23,53 \\
\hline Ecosystem Type ET (Tropical) & 1,2913 & & 0,2577 & $\begin{array}{c}< \\
0.001\end{array}$ & 5 \\
\hline $\begin{array}{l}\text { Ecosystem Type ET } \\
\text { (Upwelling) }\end{array}$ & 3,0516 & 3 & 0,3770 & $\begin{array}{c}< \\
0.001\end{array}$ & כ \\
\hline
\end{tabular}




\section{Table 2}

\begin{tabular}{lrrrr}
\hline & $\begin{array}{c}\text { Global } \\
\text { fisheries catch } \\
2000-2004\end{array}$ & $\begin{array}{c}\text { Maximum global } \\
\text { fisheries catch } \\
\text { MGFC }\end{array}$ & $\begin{array}{c}\text { Maximum global } \\
\text { fisheries catch } \\
\text { MGFC }_{75}\end{array}$ & $\begin{array}{c}\text { Maximum global } \\
\text { fisheries catch } \\
\text { MGFC }_{95}\end{array}$ \\
\hline \# of LMEs & 54 & 54 & 31 & 16 \\
Catch $\left(\times 10^{6} \mathrm{t} \mathrm{y}^{-1}\right)$ & $68(60-76)$ & $146(101-191)$ & $58(48-68)$ & $32(23-41)$ \\
\hline
\end{tabular}

Figures

Figure 1 Global marine primary production (PP) and fisheries production expressed in $(\mathrm{a}, \mathrm{c})$ catch (in $\mathrm{t}^{-1}$ ) and $(\mathrm{b}, \mathrm{d})$ primary production required $(\mathrm{PPR})$ to sustain catches (in t C $\mathrm{km}^{-2} \mathrm{y}^{-1}$ ) over the long-term period (1950-2004) and recent period (2000-2004). Solid lines indicate quantile regressions models with quantile $\tau=10 \%, 50 \%$, and $90 \%$ 
Figure 2 Slope of quantile regression as a function of quantile for $(a, c)$ catch and $(b, d)$ primary production (PP) over the long-term period (1950-2004) and recent period (2000-2004). Shaded area indicates the 95\% confidence interval 
Figure 3 Change in the $90 \%$ quantile regression slope of the relationship between primary production (PP) and primary production required to sustain catches (PPR). Solid line indicates standard deviation around estimates 


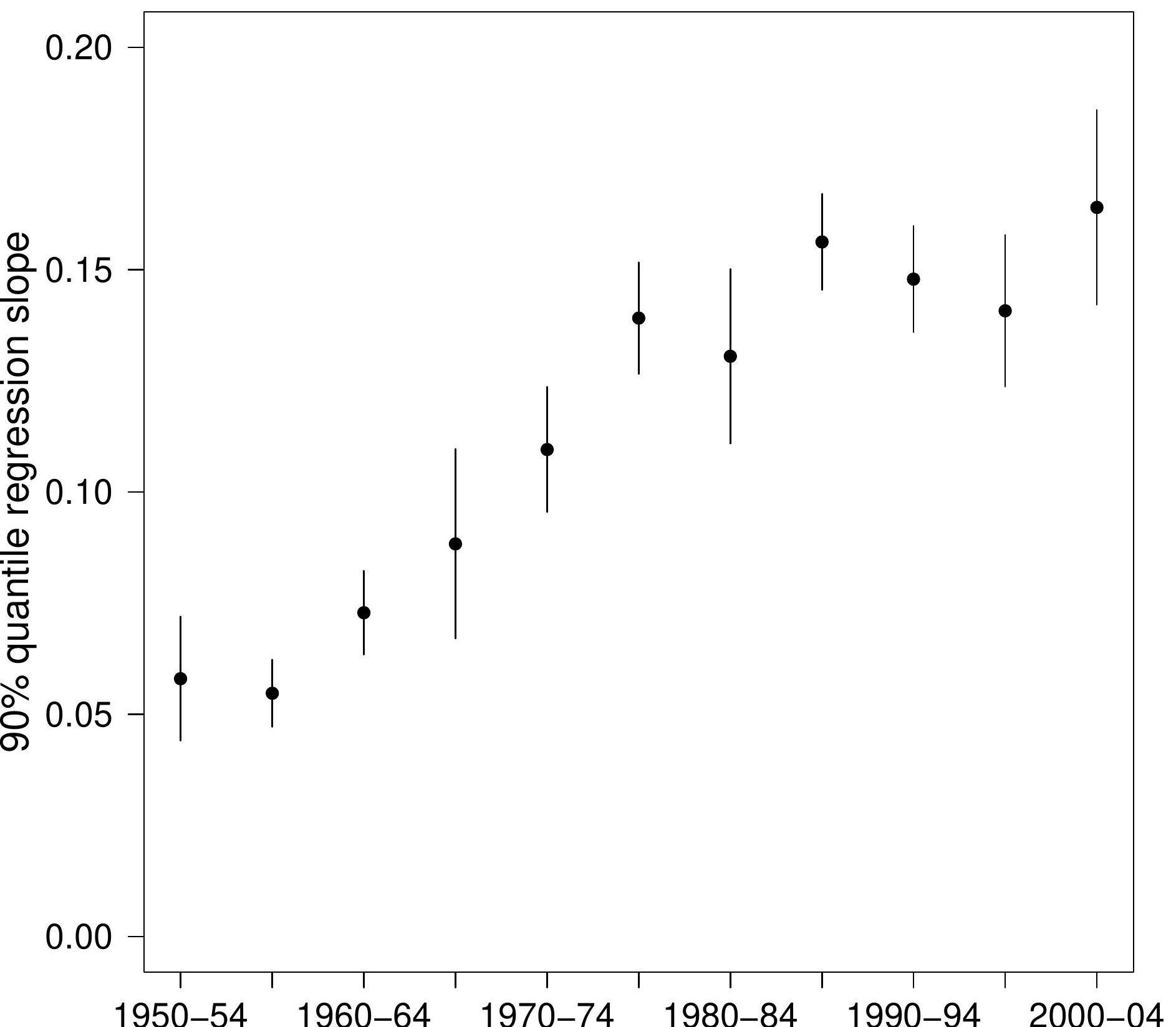

